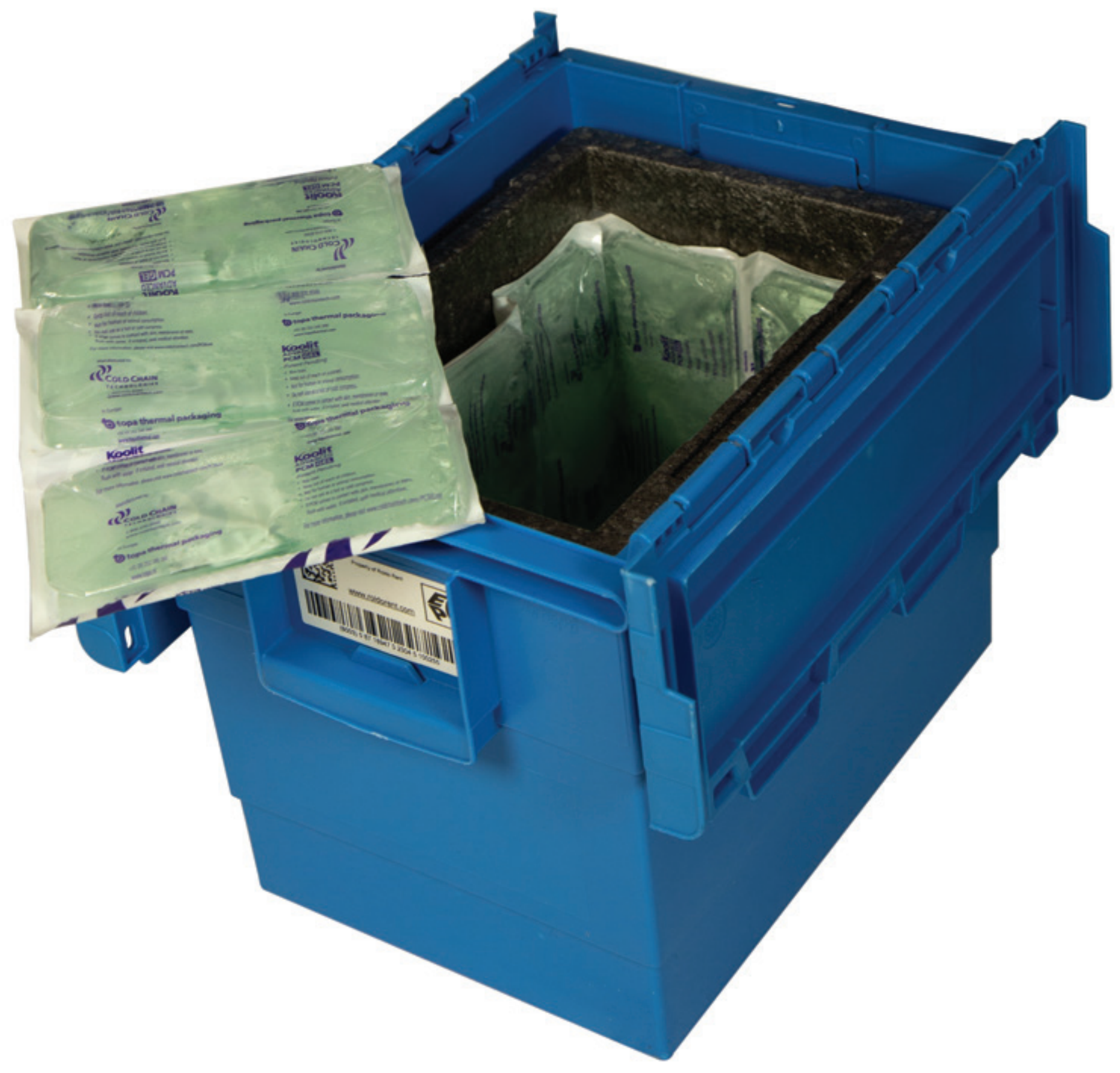

Kwalificatie testen transportbox Roldo Rent 



\section{Kwalificatie testen transportbox Roldo Rent}

Auteur: Edo Wissink

Dit onderzoek is uitgevoerd door Wageningen Food \& Biobased Research in opdracht van en gefinancierd door Roldo Rent (projectnummer 62390274-00). 
Versie: definitief

Vertrouwelijk tot en met: december 2019

Reviewer: Nicole Koenderink

Goedgekeurd door: Nicole Koenderink

Opdrachtgever: Roldo Rent

Financier: Roldo Rent

(C) 2018 Wageningen Food \& Biobased Research, instituut binnen de rechtspersoon Stichting Wageningen Research.

Vertrouwelijk rapport. Uit deze uitgave mag niets worden gereproduceerd en/of openbaar gemaakt zonder voorafgaande schriftelijke toestemming van de directeur van Wageningen Food \& Biobased Research.

Dit rapport is vanaf december 2019 gratis te downloaden op https://doi.org/10.18174/563038 of op www.wur.nl/wfbr (onder publicaties).

Postbus 17, 6700 AA Wageningen, T 03174800 84, E info.wfbr@wur.nl, www.wur.nl/wfbr. Wageningen Food \& Biobased Research is onderdeel van Wageningen University \& Research.

Alle rechten voorbehouden.

Dit rapport bestaat uit 14 pagina's en moet altijd in zijn geheel gepubliceerd worden. Niets uit deze uitgave mag worden verveelvoudigd, opgeslagen in een geautomatiseerd gegevensbestand of openbaar gemaakt in enige vorm of op enige wijze, hetzij elektronisch, hetzij mechanisch, door fotokopieën, opnamen of enige andere manier, zonder voorafgaande schriftelijke toestemming van de uitgever. De uitgever aanvaardt geen aansprakelijkheid voor eventuele fouten of onvolkomenheden. 


\section{Inhoud}

$2 \quad$ Opzet en uitvoering test $\quad 5$

$\begin{array}{lll}2.1 & \text { Box en koelelementen } & 6\end{array}$

$\begin{array}{lll}3 & \text { Resultaten } & 7\end{array}$

4 Samenvatting $r 9$

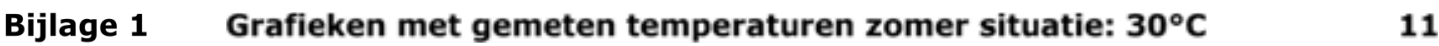

Bijlage 2 Grafieken met gemeten temperaturen normale situatie: $20^{\circ} \mathrm{C} \quad 13$

$\begin{array}{lll}\text { Bijlage } 3 & \text { Grafieken met gemeten temperaturen winter situatie: } 10^{\circ} \mathrm{C} & 14\end{array}$ 


\section{$1 \quad$ Inleiding}

Roldo Rent heeft een transportbox concept ontwikkeld gericht op het geconditioneerd distribueren van kleine hoeveelheden medicijnen en andere medische producten. Voor de kleine transportbox is de beoogde toepassing de distributie van medicijnen binnen en buiten ziekenhuizen en apotheken. Doel is dat medicijnen hygiënisch en binnen de door de GDP-richtlijn voorgeschreven temperatuurrange gedistribueerd kunnen worden.

De transportbox zelf bestaat uit een geïsoleerde box die in een kunststof krat geplaatst is. De box is voorzien van een aantal PCM koel- of verwarmingselementen. Zie foto hieronder voor een typische uitvoering. De elementen worden in deze uitvoering op de plaats gehouden met witte interne uitneembare kunststof tussenschotjes die zorgen voor de positioning van de koelelementen en voorkomen dat het product in direct contact komt met de koelelementen.

Ook is de transport box voorzien van een draadloos uitleesbare temperatuurlogger van Roldo Rent, die in de test enkel als temperatuur indicatie zijn meegenomen.

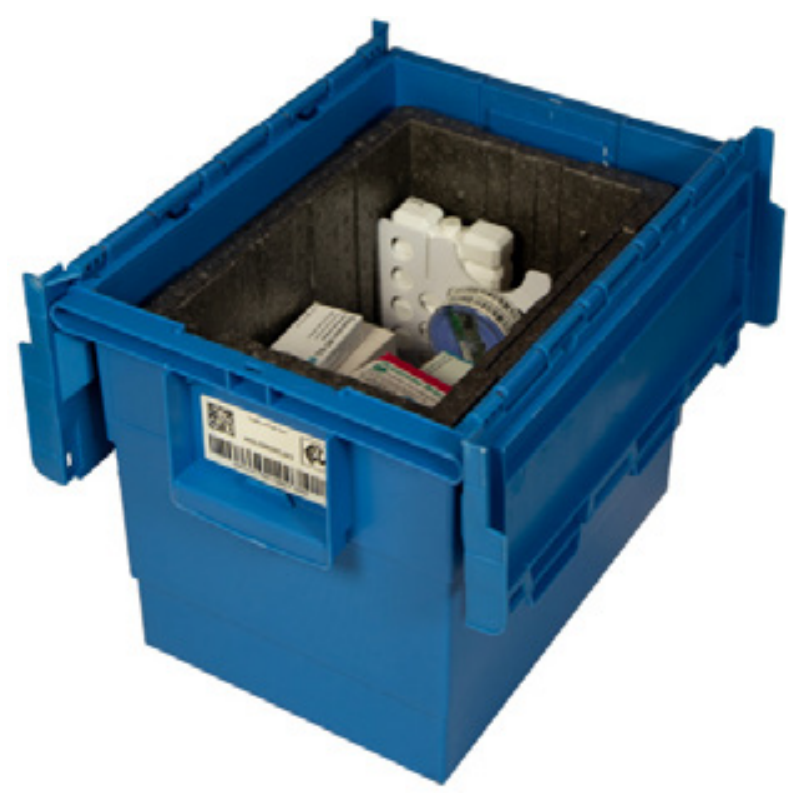

Figuur 1 Roldo Rent transportbox (bron Roldo Rent)

Roldo Rent heeft WFBR benaderd om kwalificatie metingen uit te voeren bij verschillende omgevingstemperaturen $\left(10,20\right.$ en $\left.30^{\circ} \mathrm{C}\right)$ en verschillende typen en aantallen koelelementen. Doel van de meting is vast te stellen of de koelbox goed op temperatuur komt en hoe lang het duurt voordat de temperatuur de door de GDP-richtlijn aangegeven temperatuurranges overschrijdt. 


\section{Opzet en uitvoering test}

De wens was om de boxen te testen bij drie temperatuurscenario's: Zomer $\left(T_{\text {omgeving }}=30^{\circ} \mathrm{C}\right)$, normaal $\left(T_{\text {omgeving }}=20^{\circ} \mathrm{C}\right)$ en winter $\left(T_{\text {omgeving }}=10^{\circ} \mathrm{C}\right)$. Hiervoor is onderstaande testopzet gemaakt, bestaande uit het meten van 16 metingen, waarvan de laatste drie 14, 15 en 16 op een later tijdstip zijn uitgevoerd.

Tabel 1 Opzet van testen

\begin{tabular}{|c|c|c|c|c|c|c|c|c|}
\hline & \begin{tabular}{|l|} 
\\
omgeving
\end{tabular} & \begin{tabular}{|l|} 
beoogde \\
T range
\end{tabular} & $\begin{array}{l}\text { koel } \\
\text { elementen }\end{array}$ & & $\begin{array}{l}\text { Condities } \\
\text { inzetten test }\end{array}$ & tempereren & $\begin{array}{l}\text { T_box } \\
\text { aanvang }\end{array}$ & $\begin{array}{l}\text { logger nr Roldo } \\
\text { Rent }\end{array}$ \\
\hline test $\mathrm{nr}$ & zomer & & aantal & type element & laden element & & & \\
\hline 2 & $30^{\circ} \mathrm{C}$ & $2-8^{\circ} \mathrm{C}$ & 6 & wit, water gevuld, $400 \mathrm{~g}$ & vriezer $-18^{\circ} \mathrm{C}$ & $15 \min 20^{\circ} \mathrm{C}$ & $20^{\circ} \mathrm{C}$ & HTGFOKCNRU \\
\hline 3 & $30^{\circ} \mathrm{C}$ & $2-8^{\circ} \mathrm{C}$ & 16 & groen PCM Tsmelt $=5^{\circ} \mathrm{C}, 150 \mathrm{~g}$ & vriezer $-18^{\circ} \mathrm{C}$ & niet & $20^{\circ} \mathrm{C}$ & GQQJQG7WW7 \\
\hline 4 & $30^{\circ} \mathrm{C}$ & $15-25^{\circ} \mathrm{C}$ & 16 & oranje PCM Tsmelt $=17^{\circ} \mathrm{C}, 150 \mathrm{~g}$ & koeling $4^{\circ} \mathrm{C}$ & niet & $20^{\circ} \mathrm{C}$ & GJQBWKPAZ6 \\
\hline \multirow[t]{2}{*}{15} & $30^{\circ} \mathrm{C}$ & $2-8^{\circ} \mathrm{C}$ & 6 & water gevuld, $400 \mathrm{~g}$ & vriezer $-18^{\circ} \mathrm{C}$ & $15 \min 20^{\circ} \mathrm{C}$ & $20^{\circ} \mathrm{C}$ & \\
\hline & normaal & & & & & & & \\
\hline 5 & $20^{\circ} \mathrm{C}$ & $2-8^{\circ} \mathrm{C}$ & 2 & wit, water gevuld, $400 \mathrm{~g}$ & vriezer $-18^{\circ} \mathrm{C}$ & $15 \min 20^{\circ} \mathrm{C}$ & $20^{\circ} \mathrm{C}$ & HSHZZ53FBN4 \\
\hline 6 & $20^{\circ} \mathrm{C}$ & $2-8^{\circ} \mathrm{C}$ & 4 & wit, water gevuld, $400 \mathrm{~g}$ & vriezer $-18^{\circ} \mathrm{C}$ & $15 \min 20^{\circ} \mathrm{C}$ & $20^{\circ} \mathrm{C}$ & H32LQLKQ68 \\
\hline 7 & $20^{\circ} \mathrm{C}$ & $2-8^{\circ} \mathrm{C}$ & 16 & groen, PCM Tsmelt $=5^{\circ} \mathrm{C}, 150 \mathrm{~g}$ & vriezer $-18^{\circ} \mathrm{C}$ & niet & $20^{\circ} \mathrm{C}$ & H2RHGI4UEZ \\
\hline 9 & $10^{\circ} \mathrm{C}$ & $2-8^{\circ} \mathrm{C}$ & 0 & geen & nvt & & $20^{\circ} \mathrm{C}$ & G2AHH3C2H2D \\
\hline 10 & $10^{\circ} \mathrm{C}$ & $2-8^{\circ} \mathrm{C}$ & 1 & wit, water gevuld, $400 \mathrm{~g}$ & vriezer $-18^{\circ} \mathrm{C}$ & $15 \min 20^{\circ} \mathrm{C}$ & $20^{\circ} \mathrm{C}$ & H4Z6V3A4LC \\
\hline 11 & $10^{\circ} \mathrm{C}$ & $2-8^{\circ} \mathrm{C}$ & 2 & wit, water gevuld, $400 \mathrm{~g}$ & vriezer $-18^{\circ} \mathrm{C}$ & $15 \min 20^{\circ} \mathrm{C}$ & $20^{\circ} \mathrm{C}$ & HG2Q500PGS \\
\hline 12 & $10^{\circ} \mathrm{C}$ & $2-8^{\circ} \mathrm{C}$ & 16 & groen, PCM Tsmelt $=5^{\circ} \mathrm{C}, 150 \mathrm{~g}$ & vriezer $-18^{\circ} \mathrm{C}$ & niet & $20^{\circ} \mathrm{C}$ & G7VJSALKBF \\
\hline 13 & $10^{\circ} \mathrm{C}$ & $15-25^{\circ} \mathrm{C}$ & 16 & oranje, $\mathrm{PCM}$ Tsmelt $=17^{\circ} \mathrm{C}, 150 \mathrm{~g}$ & $25^{\circ} \mathrm{C}$ cel $\left(>22^{\circ} \mathrm{C}\right)$ & niet & $20^{\circ} \mathrm{C}$ & HTVBO2UBDZ \\
\hline
\end{tabular}

Paar opmerkingen rondom het de opzet van de testen:

- Om zo goed mogelijk bij de praktijk aan te sluiten is er bewust gekozen de transportbox niet voor te koelen. Voor alle testen was de aanvangstemperatuur van de transportbox (inclusief de temperatuur loggers) $20^{\circ} \mathrm{C}$.

- $\mathrm{Bij}$ de witte watergekoelde elementen is er gekozen voor een tempereerduur van 15 minuten bij $20^{\circ} \mathrm{C}$. Langer temperen verkleint de temperatuur dip. Anderzijds is er ook initieel koelvermogen nodig om de niet voorgekoelde box te koelen.

- $\quad$ r is getest met een lege transportbox, dus zonder producten. Enkel de product loggers ("box x boven" en "box x onder") zitten verpakt in een medicijndoosje. Zie Figuur 2. Bij de positionering is er voor gezorgd dat de doosjes geen direct contact maken met de koelelementen.

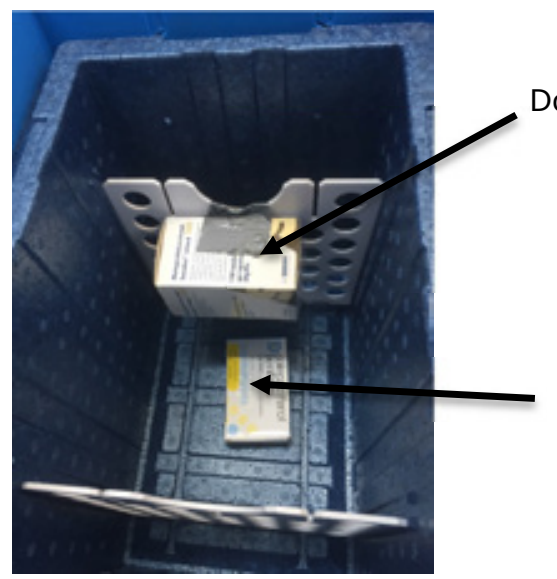

Doosje met bovenste temperatuurlogger

Doosje met onderste temperatuurlogger

Figuur 2 Temperatuur loggers in doosjes 


\section{$2.1 \quad$ Box en koelelementen}

In onderstaande tabellen zijn de eigenschappen van de geïsoleerde inzetbox gemaakt van EPP beschreven.

\begin{tabular}{|} 
Tabel 2 \\
\begin{tabular}{|l|l|l|}
\hline Isolatie box & Binnenmaat & Buitenmaat \\
\hline Lengte $[\mathrm{cm}]$ & 28 & 34.5 \\
\hline Breedte $[\mathrm{cm}]$ & 18.5 & 25.5 \\
\hline Hoogte $[\mathrm{cm}]$ & 20 & 28.5 \\
\hline & & \\
\hline Materiaal & EPP & \\
\hline
\end{tabular}
\end{tabular}

\begin{tabular}{|l|l|}
\hline $\begin{array}{l}\text { Witte water gevuld } \\
\text { koelelementen }\end{array}$ & \\
\hline $\begin{array}{l}\text { Lengte }[\mathrm{cm}] \\
\text { Breedte }[\mathrm{cm}]\end{array}$ & 17.5 \\
\hline Dikte $[\mathrm{cm}]$ & 9 \\
\hline Smeltpunt $\left[{ }^{\circ} \mathrm{C}\right]$ & 3 \\
\hline Gewicht per stuk $[\mathrm{g}]$ & 0 \\
\hline Opladen & 400 \\
\hline & $\begin{array}{l}\text { Vriezer }-18^{\circ} \mathrm{C} \text {, voor } \\
\text { gebruik } 15 \text { minuten } \\
\text { uitleggen bij } 20^{\circ} \mathrm{C}\end{array}$ \\
\hline
\end{tabular}

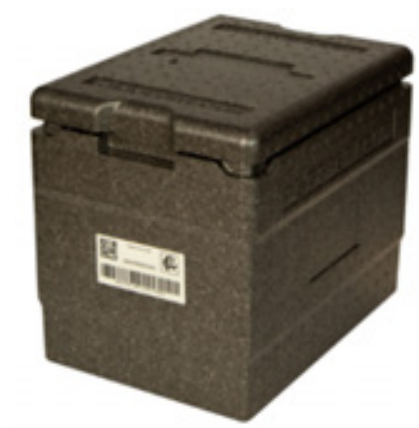

\begin{tabular}{|l|l|}
\hline $\begin{array}{l}\text { Groene PCM } \\
\text { koelelementen }\end{array}$ & \\
\hline Merk/type & Koolit/advance PCM gel \\
\hline Lengte $[\mathrm{cm}]$ & 18 \\
\hline Breedte $[\mathrm{cm}]$ & 9 \\
\hline Dikte $[\mathrm{cm}]$ & 1.5 \\
\hline Smeltpunt $\left[{ }^{\circ} \mathrm{C}\right]$ & 5 \\
\hline Gewicht per stuk $[\mathrm{g}]$ & $150(159$ gemeten $)$ \\
\hline Opladen & Vriezer $-18^{\circ} \mathrm{C}$ \\
\hline
\end{tabular}

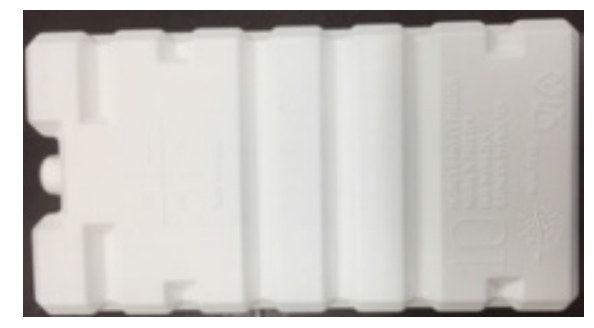

\begin{tabular}{|l|l|}
$\begin{array}{l}\text { Oranje PCM } \\
\text { verwarmelementen }\end{array}$ & Koolit/advance PCM gel \\
\hline Merk/type & 18 \\
\hline Lengte $[\mathrm{cm}]$ & 9 \\
\hline Breedte $[\mathrm{cm}]$ & 1.5 \\
\hline Dikte $[\mathrm{cm}]$ & 17 \\
\hline Stoppuntpunt $\left[{ }^{\circ} \mathrm{C}\right]$ & $150(162$ gemeten $)$ \\
\hline Gewicht per stuk $[\mathrm{g}]$ & Ruimte $25^{\circ} \mathrm{C}$ \\
\hline Opladen & \\
\hline
\end{tabular}
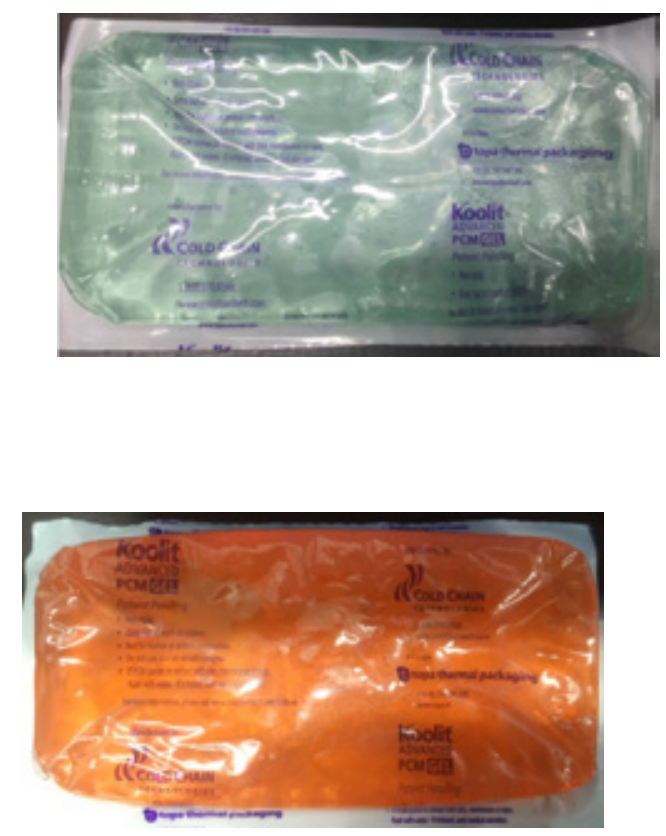


\section{Resultaten}

In bijlage 1 zijn de grafieken opgenomen van de temperatuur metingen. In de tabel hieronder staat de samenvatting van de meetresultaten.

\section{Tabel 3 Samenvatting testresultaten}

\begin{tabular}{|c|c|c|c|c|c|c|c|c|c|}
\hline & T omgeving & $\begin{array}{c}\text { koel } \\
\text { elementen }\end{array}$ & & $\begin{array}{l}\text { Condities } \\
\text { inzetten test }\end{array}$ & \begin{tabular}{|l|} 
beoogde \\
T range
\end{tabular} & $\begin{array}{c}\text { Tmin } \\
\text { box_boven }\end{array}$ & $\begin{array}{c}\text { Duur tot buiten } \\
\text { specs }\end{array}$ & $\begin{array}{c}\text { Tmin } \\
\text { box_onder }\end{array}$ & $\begin{array}{c}\text { Duur tot buiten } \\
\text { specs }\end{array}$ \\
\hline 1 & $30^{\circ} \mathrm{C}$ & 2 & wit, water gevuld, $400 \mathrm{~g}$ & vriezer $-18^{\circ} \mathrm{C}$ & $2-8^{\circ} \mathrm{C}$ & 9.1 & haalt $8^{\circ} \mathrm{C}$ niet & 11.1 & haalt $8^{\circ} \mathrm{C}$ niet \\
\hline 4 & $30^{\circ} \mathrm{C}$ & 16 & oranje PCM Tsmelt $=17^{\circ} \mathrm{C}, 150 \mathrm{~g}$ & koeling $4^{\circ} \mathrm{C}$ & $15-25^{\circ} \mathrm{C}$ & 8.8 & 54 & 7.4 & 55 \\
\hline 14 & $30^{\circ} \mathrm{C}$ & 5 & water gevuld, $400 \mathrm{~g}$ & vriezer $-18^{\circ} \mathrm{C}$ & $2-8^{\circ} \mathrm{C}$ & 7.2 & 4 & 2.5 & 25 \\
\hline 15 & $30^{\circ} \mathrm{C}$ & 6 & water gevuld, $400 \mathrm{~g}$ & vriezer $-18^{\circ} \mathrm{C}$ & $2-8^{\circ} \mathrm{C}$ & 6.7 & 10 & 2.2 & 30 \\
\hline 6 & $20^{\circ} \mathrm{C}$ & 4 & wit, water gevuld, $400 \mathrm{~g}$ & vriezer $-18^{\circ} \mathrm{C}$ & $2-8^{\circ} \mathrm{C}$ & 1.9 & 36 & 2.9 & 37 \\
\hline 7 & $20^{\circ} \mathrm{C}$ & 16 & groen, $\mathrm{PCM}$ Tsmelt $=5^{\circ} \mathrm{C}, 150 \mathrm{~g}$ & vriezer $-18^{\circ} \mathrm{C}$ & $2-8^{\circ} \mathrm{C}$ & -5.5 & 37 & -8.6 & 43 \\
\hline 8 & $20^{\circ} \mathrm{C}$ & 0 & geen & nvt & $15-25^{\circ} \mathrm{C}$ & nvt & oneindig & nvt & oneindig \\
\hline \multirow[t]{2}{*}{16} & $20^{\circ} \mathrm{C}$ & 5 & water gevuld, $400 \mathrm{~g}$ & vriezer $-18^{\circ} \mathrm{C}$ & $2-8^{\circ} \mathrm{C}$ & 5.2 & 30 & 1.5 & 44 \\
\hline & winter & & & & & & & & \\
\hline 13 & $10^{\circ} \mathrm{C}$ & 16 & oranje, $\mathrm{PCM}$ Tsmelt $=17^{\circ} \mathrm{C}, 150 \mathrm{~g}$ & $25^{\circ} \mathrm{C}$ cel & $15-25^{\circ} \mathrm{C}$ & nvt & 79 & nvt & 78 \\
\hline
\end{tabular}

In de laatste 4 kolommen zijn de meetresultaten verwerkt: de minimaal gemeten temperatuur en de duur dat de grens van de beoogde T-range wordt gehaald. Dit is voor zowel de bovenste logger, als de onderste logger in de box weergegeven. De waardes spreken voor zich: <namelijk?>. Wel moet opgemerkt worden dat er in de praktijk altijd afwijkingen condities zullen zijn, zodat de gemeten waardes enkel als indicatieve waardes beschouwd mogen worden.

Test 2 is weggelaten uit de tabel omdat deze onbetrouwbare/niet logisch resultaten liet zien en is vervangen door de aanvullende testen 14 en 15.

Toelichting kolom "Tmin box"

Omdat er getest is met een lege box, is er veelal een temperatuurdip na het inzetten van de test zichtbaar. De gemeten is een extreme waarde die enkel gunstiger kan worden als er producten in de koelbox zitten. Als dit niet acceptabel is, dan kan het voorkomen worden door proefondervindelijk de elementen langer uit leggen in een warme ruimte (test: 15 minuten bij $20^{\circ} \mathrm{C}$ ), maar dan wel te starten met een voorgekoelde transportbox (test: box gestabiliseerd bij $20^{\circ} \mathrm{C}$ ).

Toelichting kolommen "duur tot buiten specs"

In de test zijn twee GDP-temperatuur ranges beschouwd: 15 tot $25^{\circ} \mathrm{C}$ (ambient) voor test 4, 8 en 13 en voor de overige 2 tot $8^{\circ} \mathrm{C}$ (gekoeld). De duur is de tijd vanaf begin van de test waar de box langzaam maar zeker (dus na de initiële temperatuur dip/schommeling) de grens van de GDP range overschrijdt. Voor gekoeld is dat de $8^{\circ} \mathrm{C}$ grens. De $8^{\circ} \mathrm{C}$ zal uiteindelijk altijd overschreden worden omdat er getest is bij hogere omgevingstemperaturen $\left(10,20\right.$ en $\left.30^{\circ} \mathrm{C}\right)$. 
Praktische bevinding tijdens inzetten van test

Wat tijdens het testen naar voren kwam is dat in de situaties met 16 koelelementen deze niet goed passen in de transportbox. De deksel kan niet/zeer moeilijk volledig gesloten worden, als de koelelementen zoals voorgeschreven rondom het product moeten worden toegepast. Zie figuur hieronder. Het advies is om in dit geval 12 elementen te gebruiken (weglaten van de elementen op de bodem)

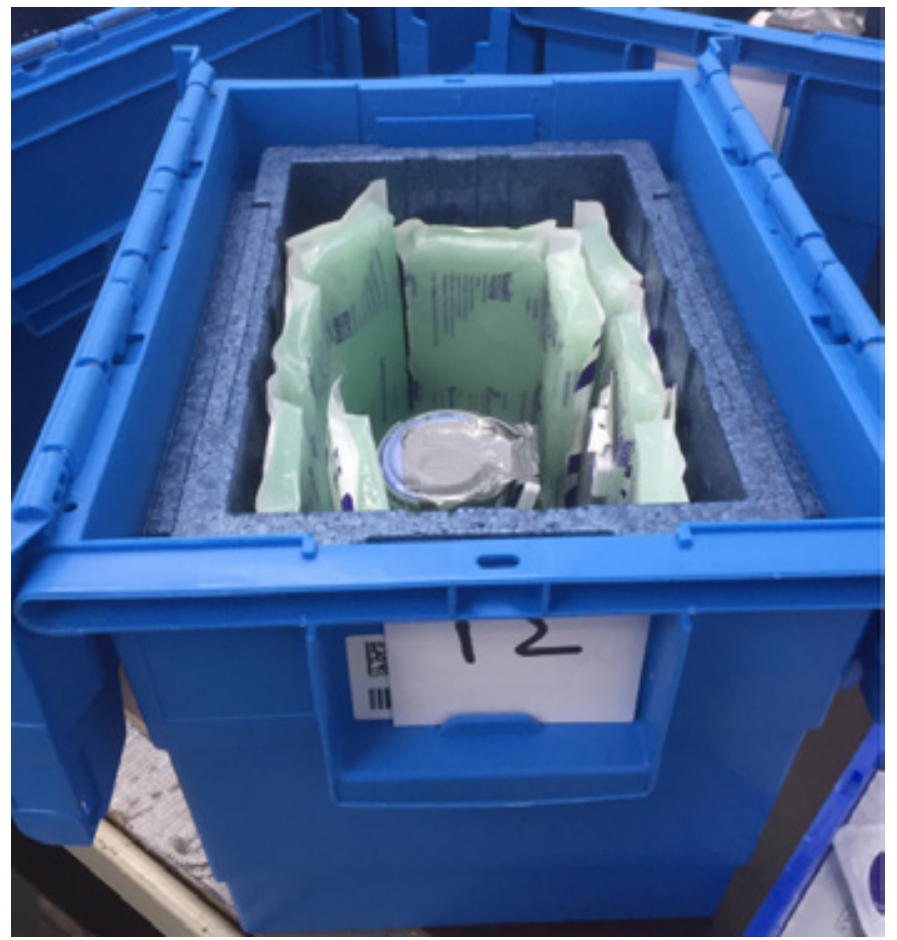

Figuur 3 Transportbox met 12 elementen van $150 \mathrm{~g}$ waar er dus nog 3 bovenop moeten. Past eigenlijk niet meer in de hoogte waardoor deksel niet of zeer moeilijk sluit. 


\section{$4 \quad$ Samenvatting}

WFBR heeft in opdracht van Roldo Rent kwalificatie testen uitgevoerd voor de kleine transportbox. Doel van de meting is vast te stellen of de koelbox goed op temperatuur komt en hoe lang het duurt voordat de temperatuur de door de GDP-richtlijn aangegeven temperatuurranges overschrijdt. Dit is uitgevoerd in de extreme situatie met lege niet voorgekoelde koelboxen.

Er zijn in totaal 16 configuraties getest, bij drie omgevingstemperaturen $\left(10,20\right.$ en $\left.30{ }^{\circ} \mathrm{C}\right)$ en daarbij zijn verschillende type en aantallen koelelementen toegepast. In de tabel hieronder staat de samenvatting van de meetresultaten. Opgemerkt moet worden dat er in de praktijk altijd afwijkende condities zullen zijn, zodat de gemeten waardes enkel als indicatieve waardes beschouwd mogen worden. Voor het valideren van een verzendproces kan WRBR de validatie uitvoeren of mogelijk volstaat het toepassen van de temperatuur logger van Roldo Rent.

\section{Tabel 4 Samenvatting testresultaten}

Indicatieve verblijftijd voor categorie $\left[2-8^{\circ} \mathrm{C}\right]$ in uren op basis gemiddelde gemeten box temperatuur

\begin{tabular}{|c|c|c|c|c|}
\hline & $\begin{array}{c}16 \times 150 \mathrm{~g} \\
\text { groen }\end{array}$ & 112 uur & 40 uur & 17 uur \\
\hline \multirow{8}{*}{ 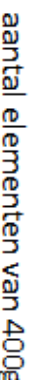 } & 6 & & & 20 uur \\
\hline & 5 & & 37 uur & 14 uur \\
\hline & 4 & & 36 uur & \\
\hline & 3 & & & \\
\hline & 2 & 44 uur & 17 uur & \\
\hline & 1 & 27 uur & & \\
\hline & 0 & & & \\
\hline & & $10^{\circ} \mathrm{C}$ & $20^{\circ} \mathrm{C}$ & $30^{\circ} \mathrm{C}$ \\
\hline
\end{tabular}

Indicatieve verblijftijd voor categorie $\left[15-25^{\circ} \mathrm{C}\right]$ in uren op basis gemiddelde gemeten box temperatuur

\begin{tabular}{|c|c|c|c|c|}
\hline \multirow{2}{*}{ 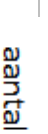 } & $\begin{array}{c}16 \times 150 \mathrm{~g} \\
\text { oranje }\end{array}$ & 78 uur & & 54 uur \\
\hline & 5 & & & \\
\hline$\frac{D}{D}$ & 4 & & & \\
\hline 8 & 3 & & & \\
\hline$\vec{D}$ & 2 & & & \\
\hline S & 1 & & & \\
\hline ב & 0 & & oneindig & \\
\hline & & $10^{\circ} \mathrm{C}$ & $20^{\circ} \mathrm{C}$ & $30^{\circ} \mathrm{C}$ \\
\hline
\end{tabular}


文

อ

$\varepsilon$

ต

ฮั

(1)

\begin{tabular}{ll} 
c & \multicolumn{1}{c}{} \\
0 & $\frac{1}{0}$ \\
0 & $\frac{0}{0}$ \\
0 & $\frac{1}{1}$ \\
& $\frac{1}{y}$
\end{tabular}

ป⿱一兀)

도

(1)

है 


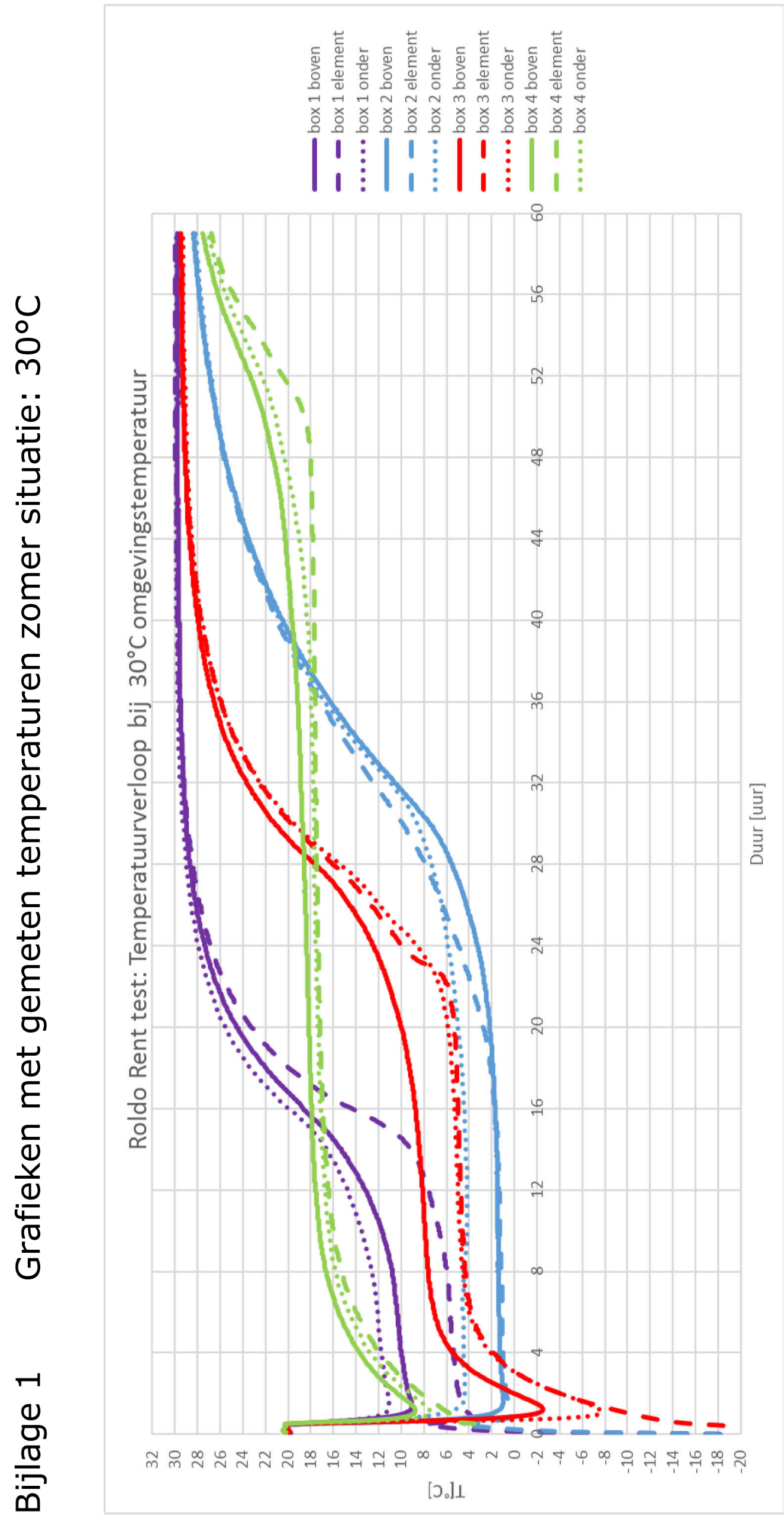




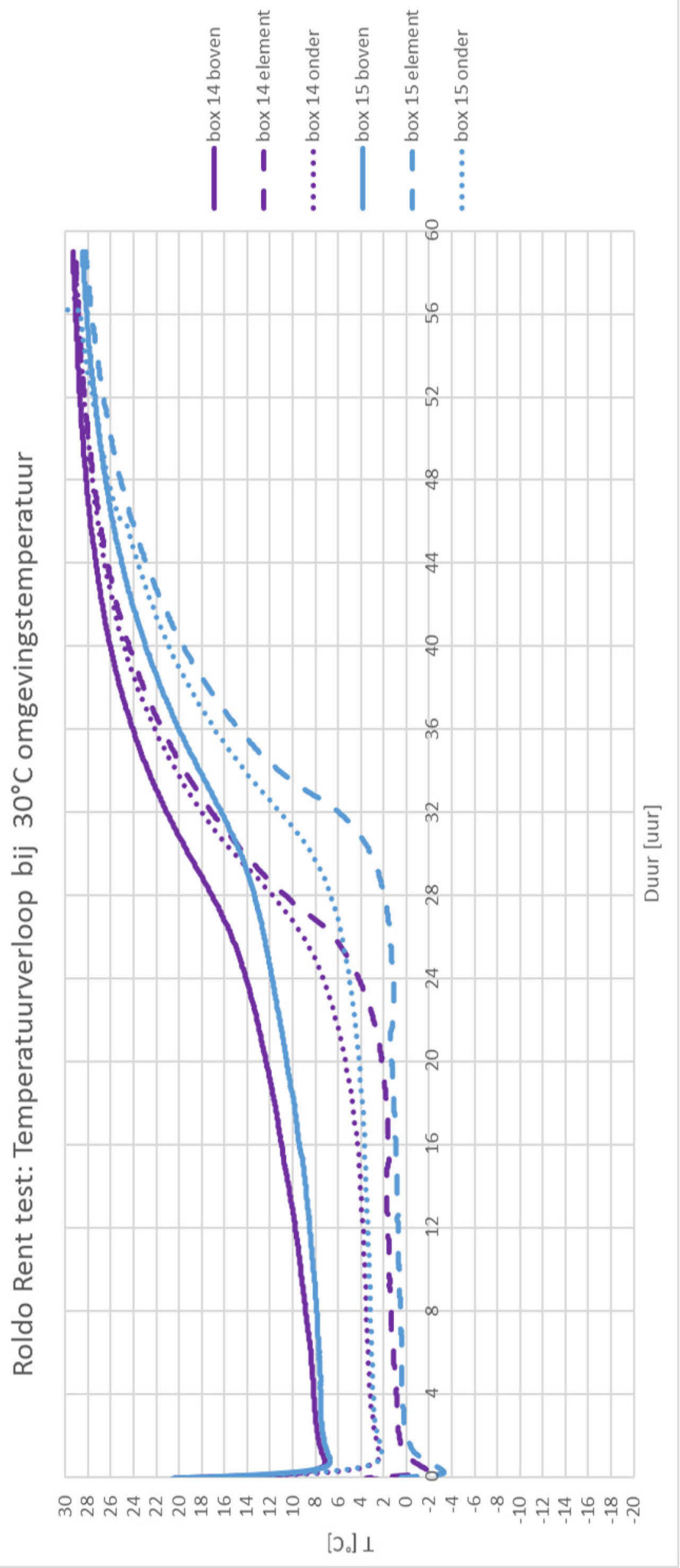




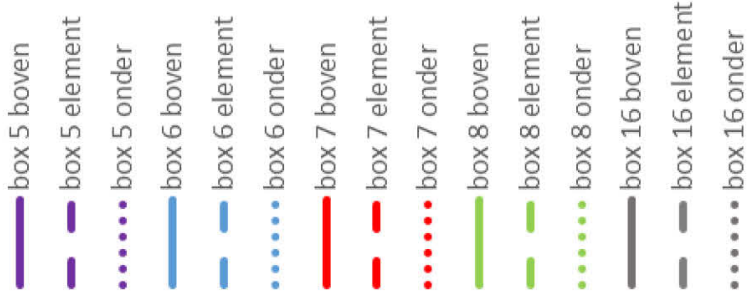

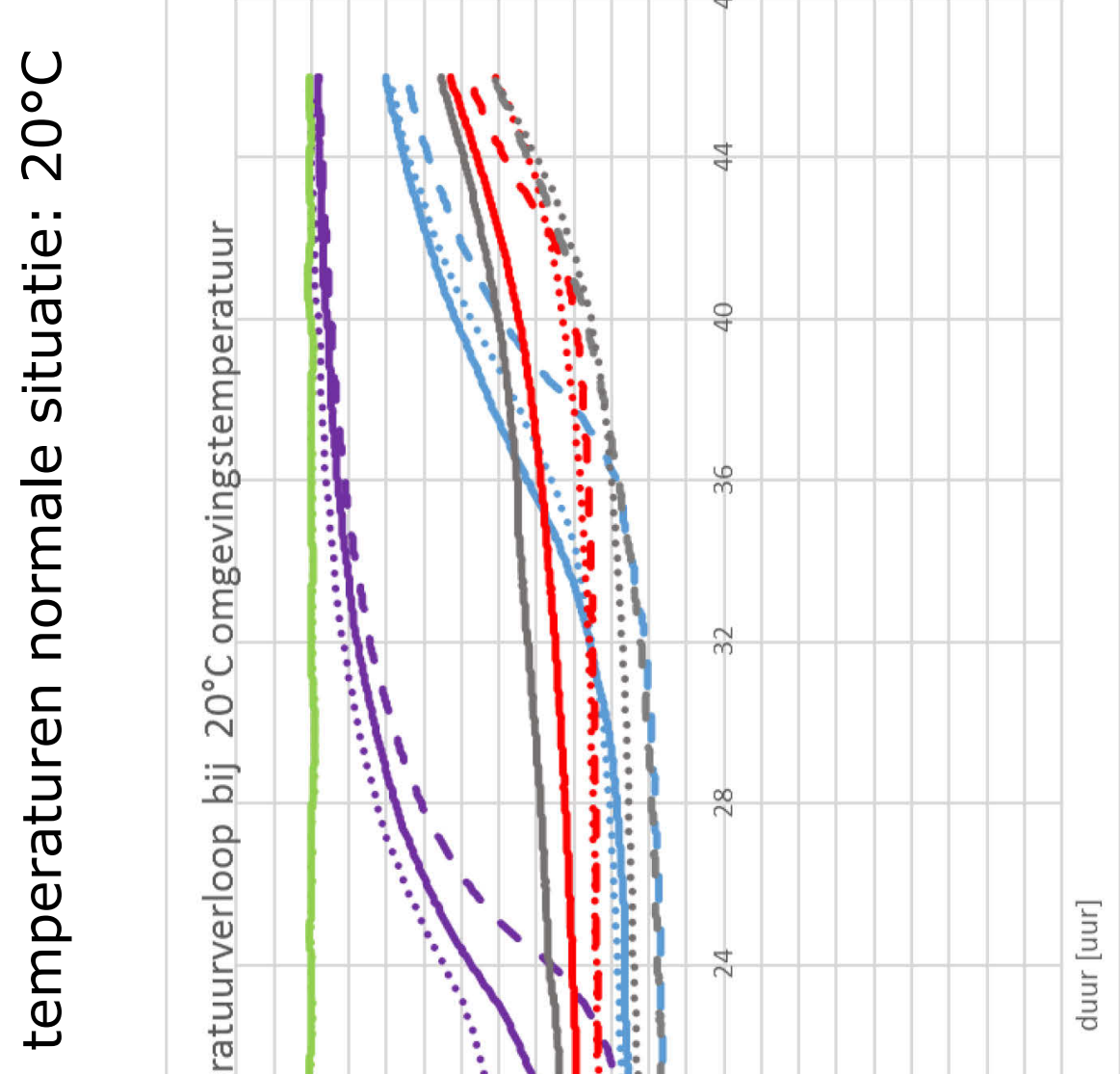

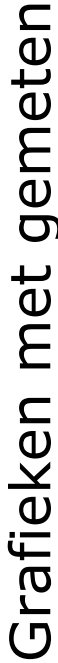

N

o

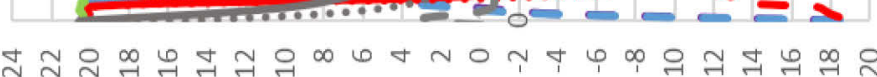

[ว.] $\perp$ 

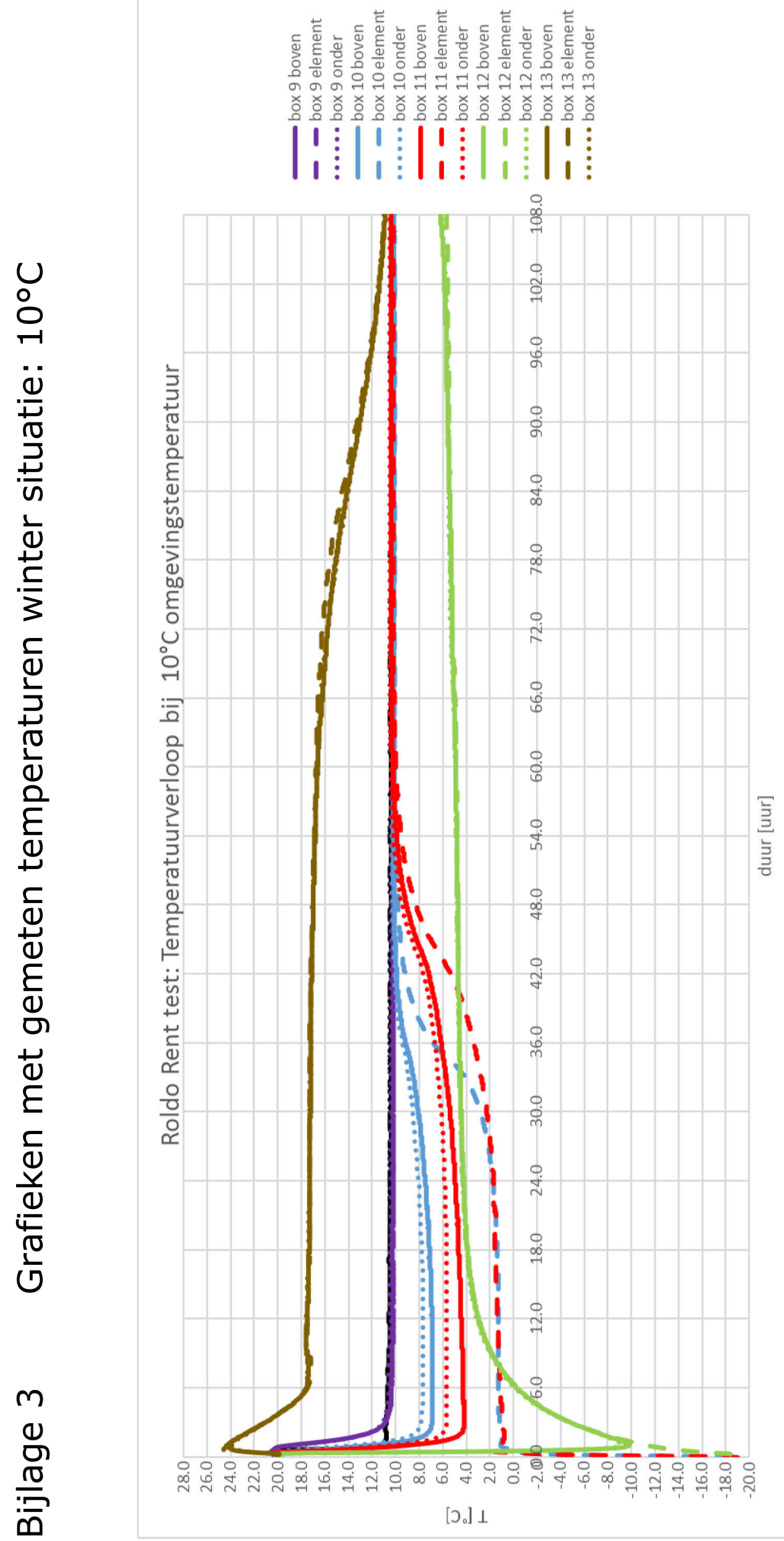



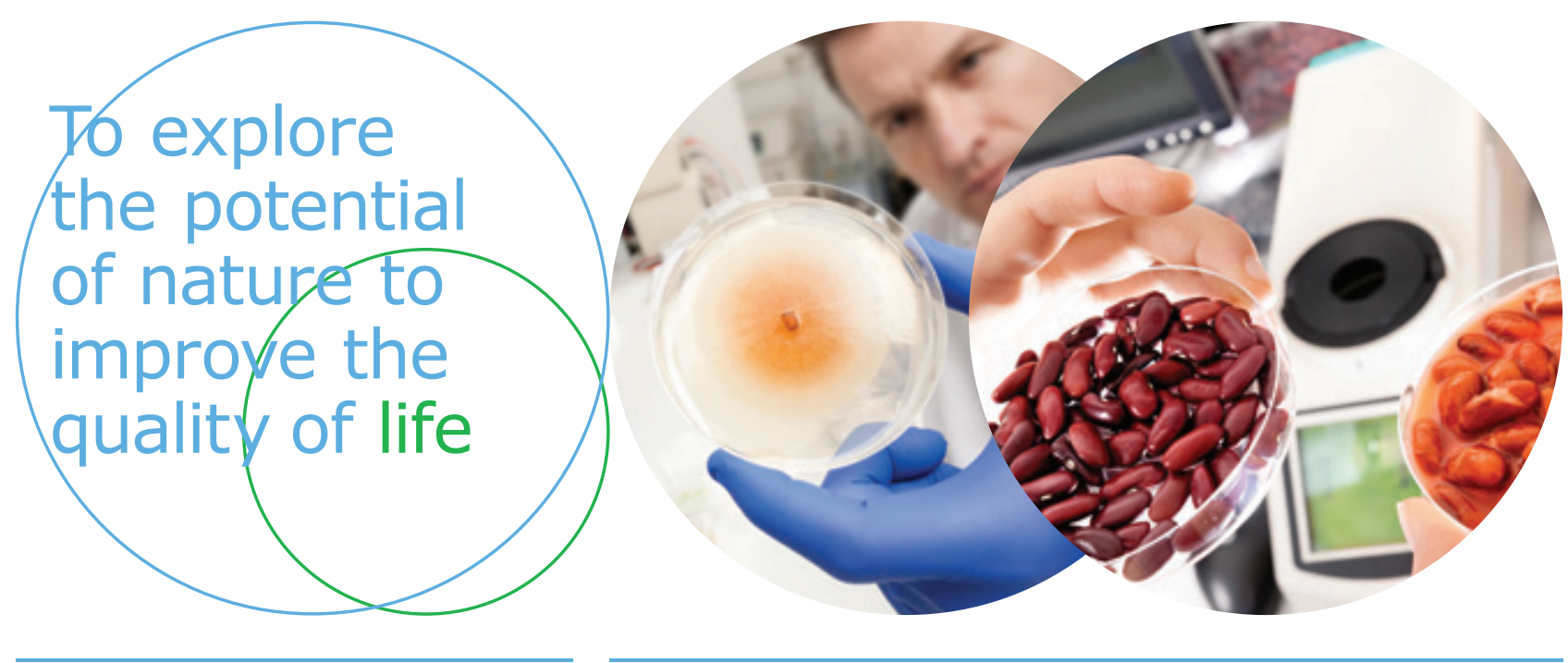

Wageningen Food \& Biobased Research Bornse Weilanden 9

6708 WG Wageningen

www.wur.nl/wfbr

info.wfbr@wur.nl

Rapport 1893
De missie van Wageningen University \& Research is 'To explore the potential of nature to improve the quality of life'. Binnen Wageningen University \& Research bundelen Wageningen University en gespecialiseerde onderzoeksinstituten van Stichting Wageningen Research hun krachten om bij te dragen aan de oplossing van belangrijke vragen in het domein van gezonde voeding en leefomgeving. Met ongeveer 30 vestigingen, 5.000 medewerkers en 10.000 studenten behoort Wageningen University \& Research wereldwijd tot de aansprekende kennisinstellingen binnen haar domein. De integrale benadering van de vraagstukken en de samenwerking tussen verschillende disciplines vormen het hart van de unieke Wageningen aanpak. 